\title{
Adult Cleft Lip Repair under Local Anaesthesia: The Ghana Experience
}

\section{Solomon Obiri-Yeboah"1,2, Micheal Yeliborah', Alexander Oti Acheampong1,2, Samuel Kodjo Ansah"1, John H. Grant ${ }^{3}$, Peter Donkor ${ }^{1,2}$}

${ }^{1}$ Kwame Nkrumah University of Science and Technology, Kumasi, Ghana

${ }^{2}$ Komfo Anokye Teaching Hospital, Kumasi, Ghana

${ }^{3}$ University of Alabama at Birmingham, Alabama Children's Hospital, Birmingham, AL, USA

Email: obiriyeb@yahoo.com

How to cite this paper: Obiri-Yeboah, S. Yeliborah, M., Acheampong, A.O., Ansah, S.K., Grant, J.H. and Donkor, P. (2016) Adult Cleft Lip Repair under Local Anaesthesia: The Ghana Experience. Modern Plastic Surgery, 6, 27-32.

http://dx.doi.org/10.4236/mps.2016.64005

Received: August 30, 2016

Accepted: September 26, 2016

Published: September 29, 2016

Copyright $\odot 2016$ by authors and Scientific Research Publishing Inc. This work is licensed under the Creative Commons Attribution International License (CC BY 4.0).

http://creativecommons.org/licenses/by/4.0/

\begin{abstract}
Background: Unlike developed countries where adult primary cleft lip and palate cases are barely nonexistent, developing countries still have a backlog of adults with unrepaired cleft lip and palate. Method: A retrospective review of adult/adolescent cleft lip repair under local anesthesia was performed between 2012 and 2015 . Results: Fifty six (56) adolescent and adults were seen comprising 35 females and 21 males. Forty two patients presented with unrepaired unilateral cleft lip of which only 6 were complete; 4 were unrepaired bilateral cleft lip and 10 were revisions. The lowest age was 13 years (two patients) and the highest age was 66 years (one patient). The mean weight was $54 \mathrm{~kg}$. The mean anaesthetic time including waiting time was 12.94 minutes and mean operation time was 56.52 minutes. Majority of the patients were discharged same day except for five who needed to stay overnight because of distance from their home. There were no reported early postoperative complications and wound healing was uneventful for all the patients. Conclusion: Cleft lip repair in adults under local anesthesia is safe, effective and less expensive. A modification in technique with minimal dissection and efficiency is essential in such cases.
\end{abstract}

\section{Keywords}

Adult, Adolescent, Cleft Lip, Local Anaesthesia

\section{Background}

Cleft lip and palate is among the most common congenital malformations with complex multifactorial etiology including both genetic and environmental factors [1]. Although numerous techniques and protocols are employed in the repair of this condition, the surgical literature is consistent in recommending early repair, typically 
completing primary repair of the lip and palate by the age of two years [2]. A commonly accepted protocol in many centers and surgical textbooks is the use of the Rule of $10 \mathrm{~s}$. The minimum age should be 10 weeks, the weight at least $10 \mathrm{lb}$ and have at least an $\mathrm{Hb}$ of $10 \mathrm{~g} / \mathrm{dl}$. Cheiloplasty is then followed by primary palatoplasty at nine months and over before development of speech [1]-[4].

It is well known that timely closure of a palatal defect is associated with improved speech outcome [3], and late closure of the palate has been clearly demonstrated to give a poor outcome [4]. In addition, delayed repair of the cleft can lead to impaired family and societal relationships with potential long-term psychological effects on the child [5]. In contrast to developed countries where adult primary cleft lip and palate cases are barely nonexistent, developing countries still have a backlog of adults with unrepaired cleft lip and palate. Patients often present to the surgeon far past the optimal time for closure of the cleft deformities [2] [3]. The potential reasons for this are many, including distance to health facility, limited access to specialized health care, lack of awareness of treatment availability, cultural beliefs, superstition, and lack of money or time [2] [3] [6] [7].

Developing countries often lack the equipment and personnel to provide general anaesthesia for all patients. Secondly, general anaesthesia is expensive, and more time and personnel are required, therefore a safe technique for repair under local anaesthesia would be useful. In this review, we present our experience with adult cleft lip repair under local anesthesia (LA) alone without intravenous (IV) sedation.

\section{Patients and Method}

An IRB approved retrospective review of adolescent/adult primary and secondary cleft lip repair under LA at the Komfo Anokye Teaching Hospital (KATH) in Ghana.

Patients, who underwent repair using only LA between January 2012 and December 2015 were included.

This technique was used on consenting adolescents and adults aged 13 years or more with microform, unilateral or bilateral unrepaired left lip or requiring a revision of a previous repair, and had the ability to understand and tolerate the procedure under LA alone.

Bilateral infraorbital nerve block was done for those with complete cleft in addition to local infiltration. All patients were assessed clinically and the procedure was explained to the patients and/or legal guardian for informed consent. Consent for patients below 18 years was obtained from both the legal guardian and the patient.

Patients who were not medically fit or were unable to tolerate the procedure while awake were excluded. Demographic information and outcome data were collected including average time to achieve anaesthesia, surgical time, and day of discharge.

\subsection{Protocol}

Patients were counselled and procedure explained to them in their comfortable dialect. On the operating table patient was informed on introduction of the needle for injection 
of LA and first incision. Constant communication was kept with patients to assure them about the progress of the surgery. This helped to minimize anxiety.

\subsection{Anaesthesia}

Local infiltration without nerve block was used for those with microform and incomplete cleft lip without significant nasal deformity. LA containing $2 \%$ lidocaine with adrenaline 1:80,000 was infiltrated into the non-cleft, cleft sides of the lip and the base of the ala of the nose after marking the aesthetic points and units. LA cartridge with 1.8 $\mathrm{mls}$ of $2 \%$ lidocain with adrenaline $1: 80,000$ contains $36 \mathrm{mg}$ of lidocaine and $22.5 \mathrm{mi}$ crograms of adrenaline, with duration of action being between 140 and 240 minutes.

Infraorbital nerve block coupled with local infiltration was used for those with complete cleft, severe nasal deformity and bilateral nerve block for those with bilateral cleft lip.

\subsection{Surgical Technique}

Modified Millard's, Mohler's and Tennison's triangular techniques were used depending on surgeons preference. All the patients tolerated the procedure so well, and there was no complication recorded or patient complaining of pain in the middle of the procedure.

All the patients were discharge home the same day except five who were kept overnight for distance from home and lack of means transport.

\section{Results}

Fifty six (56) adolescents and adults were seen. Thirty five (62\%) females and Twenty one $(38 \%)$ were males. Forty two $(75 \%)$ of the patients presented with unilateral cleft lip of which only six (14.3\%) were complete; Four (7\%) were bilateral cleft lip and ten (18\%) required lip revisions. The mean age was 24.32 years and ranged from 13 years (two patients) to 66 years (one patient). The mean weight was $54 \mathrm{~kg}$. The mean time to achieve anaesthesia was 12.94 and mean duration of surgery was 56.52 minutes. Majority of the patients were discharged same day except for five who needed to stay overnight because of distance from their home. There were no reported early postoperative complications and wound healing was uneventful for all the patients (Figures 1-4).

\section{Discussion}

Unlike developed countries, where adult cleft lip is virtually non-existent, Ghana and other developing countries still have a backlog of adolescent and adult cleft lip and/or palate.

The potential reasons for late reporting in Ghana may not be different from what is reported from other neighbouring and developing countries. These include distance to health care, limited access to specialized health care, unavailability of health care services, lack of awareness of treatment availability, cultural beliefs, superstition, and lack of money or time [5]-[9]. 


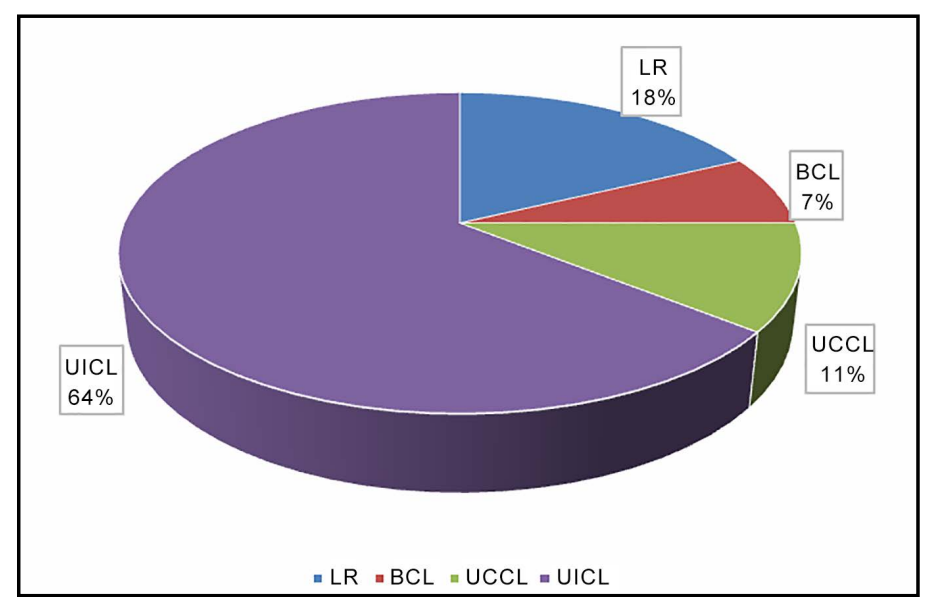

Figure 1. Type of cleft: LR (Lip Revision), BCL (Bilateral Cleft Lip), UCCL (Unilateral Complete Cleft Lip), UICL (Unilateral Incomplete Cleft Lip).
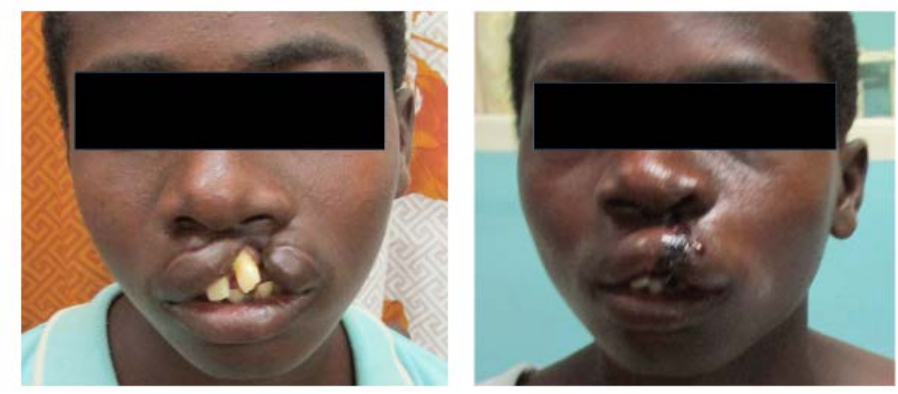

Figure 2. Before and after picture a thirteen-year-old boy with incomplete cleft lip and alveolus.
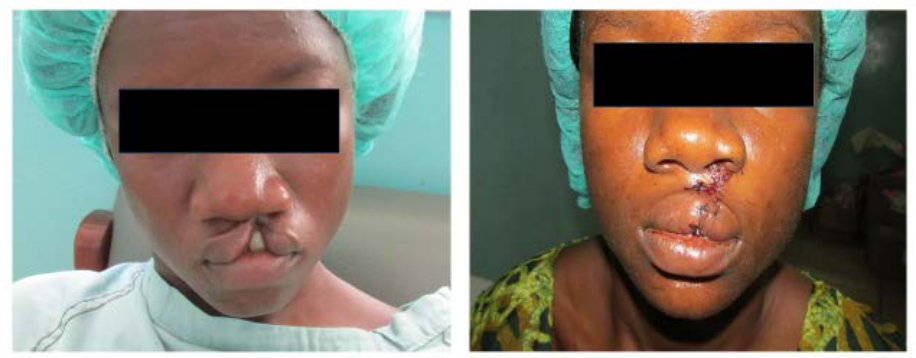

Figure 3. Before and after picture a twenty-five-year-old lady with an incomplete lip with Simonart band.

In our centre majority of patients with primary cleft lip and palate are below the age of one year and are referred soon after birth from other hospitals and maternity homes.

In this review 33 adolescents and adults were identified. Ninety percent (90\%) of them were seen during cleft surgery outreach visits to other regions in Ghana where specialist services are lacking. A few of the patients were brought to our centre by benevolent NGOs and our visitation team from rural areas. 

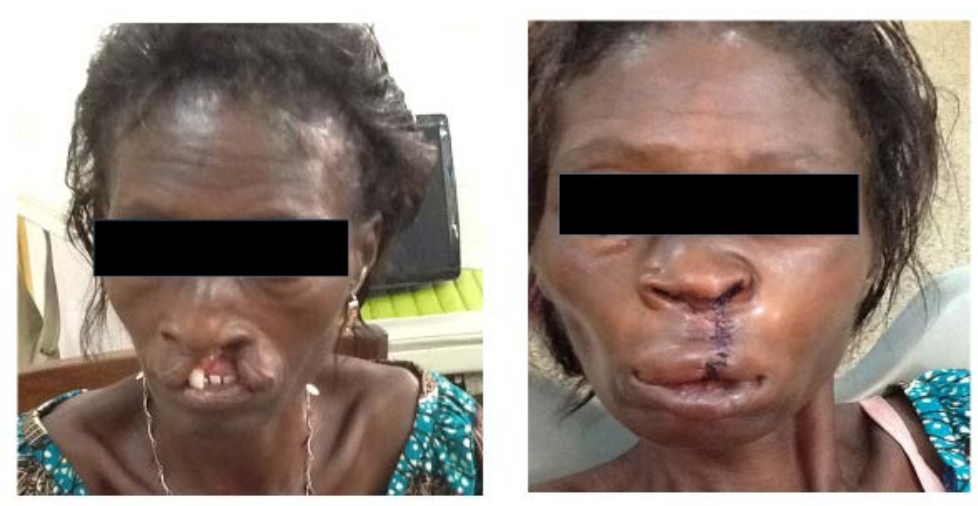

Figure 4. Before and after picture of fifty-five-year-old woman with complete cleft lip and alveolus.

This procedure has been used and still being used by many centres in Africa, other developing countries and missionary teams, and we agree with previous reports that this procedure is safe, effective and inexpensive [9]-[11]. We believe it might even be a better option in terms of cost for adult patients (if any) even in developed countries. We believe that this technique can be improved to be more comfortable and better tolerated by patients.

\section{Conclusion}

Cleft lip repair in adults under local anaesthesia is safe, effective and inexpensive. A modification in technique with minimal dissection and efficiency may, however, be essential to reduce any discomfort.

\section{Acknowledgements}

The authors acknowledge the Multidisciplinary cleft team of Komfo Anokye Teaching Hospital and the Ghana Cleft Foundation for their commitment to free cleft surgery outreach to deprived regions in Ghana, the source of a greater percentage of the data for this study.

\section{References}

[1] Eberlin, K.R., Vyas, R.M., Abi-Haidar, Y., Sethna, N. and Hamdan, U.S. (2013) Adult Cleft Lip Repair under Local Anesthesia: An Effective Technique in Resource-Poor Settings. The Cleft Palate-Craniofacial Journal, 50, 59-63. http://dx.doi.org/10.1597/11-256

[2] Hodges, S.C. and Hodges, A.M. (2001) A Protocol for Safe Anasthesia for Cleft Lip and Palate Surgery in Developing Countries. Anaesthesia, 55, 436-441. http://dx.doi.org/10.1046/j.1365-2044.2000.01371.x

[3] Tremlett, M. (2004) Anaesthesia for Cleft Lip and Palate Surgery. Current Anaesthesia and Critical Care, 15, 309-316. http://dx.doi.org/10.1016/j.cacc.2004.09.003

[4] Olasoji, H.O., Dogo, D. and Arotiba, G.T. (2002) Experience with Unoperated Cleft Lip and Palate in a Nigerian Teaching Hospital. Tropical Doc, 32, 33-36.

[5] Aziz, S.R. and Rhee, S.T. (2009) Redai Cleft Surgery in Rural Bangladesh: Reflections and 
Experiences. Journal of Oral and Maxillofacial Surgery, 67, 1581-1588.

http://dx.doi.org/10.1016/j.joms.2008.11.021

[6] Schwarz, R. and Khadka, S.B. (2004) Reasons for Late Presentation of Cleft Deformity in Nepal. The Cleft Palate-Craniofacial Journal, 41, 199-201. http://dx.doi.org/10.1597/03-016

[7] Nwoku, A.L. (1974) Experience on Repair of Unoperated Cleft Patients. Nigerian Medical Journal, 6, 417-421.

[8] Donkor, P., Bankas, D.O., Agbenorku, P., Plange-Rhule, G. and Ansah, S.K. (2007) Cleft Lip and Palate in Kumasi, Ghana: 2001-2005. Journal of Craniofacial Surgery, 18, 13761379. http://dx.doi.org/10.1097/01.scs.0000246504.09593.e4

[9] Adeyemo, W.L., Ogunlewe, M.O., Desalu, I., Ladeinde, A.L., Mofikoya, B.O., Adeyemi, M.O. and Adepoju, A.A. (2009) Cleft Deformities in Adults and Children Aged over Six Years in Nigeria: Reasons for Late Presentation and Management Challenges. Clinical, Cosmetic and Investigational Dentistry, 2009, 63-69.

https://dx.doi.org/10.2147/CCIDE.S6686

[10] Adekeye, E.O. and Lavery, K.M. (1985) Cleft Lip and Palate in Nigerian Children and Adults: A Comparative Study. British Journal of Oral and Maxillofacial Surgery, 23, 398403. http://dx.doi.org/10.1016/0266-4356(85)90023-3

[11] Ahmad, M. (2008) Cleft Lip Repair under Local Anesthesia in Adults. Journal of Surgery Pakistan, 13, 170-172.

Submit or recommend next manuscript to SCIRP and we will provide best service for you:

Accepting pre-submission inquiries through Email, Facebook, LinkedIn, Twitter, etc. A wide selection of journals (inclusive of 9 subjects, more than 200 journals)

Providing 24-hour high-quality service

User-friendly online submission system

Fair and swift peer-review system

Efficient typesetting and proofreading procedure

Display of the result of downloads and visits, as well as the number of cited articles

Maximum dissemination of your research work

Submit your manuscript at: http://papersubmission.scirp.org/

Or contact mps@scirp.org 